\title{
Efficient solution of the non-linear Reynolds equation for compressible fluid using the
} finite element method

\author{
Larsen, Jon Steffen; Santos, IImar
}

Published in:

Journal of the Brazilian Society of Mechanical Sciences and Engineering

Link to article, DOI:

$10.1007 / \mathrm{s} 40430-014-0220-5$

Publication date:

2015

Document Version

Publisher's PDF, also known as Version of record

Link back to DTU Orbit

Citation (APA):

Larsen, J. S., \& Santos, I. (2015). Efficient solution of the non-linear Reynolds equation for compressible fluid using the finite element method. Journal of the Brazilian Society of Mechanical Sciences and Engineering, 37(3), 945-957. https://doi.org/10.1007/s40430-014-0220-5

\section{General rights}

Copyright and moral rights for the publications made accessible in the public portal are retained by the authors and/or other copyright owners and it is a condition of accessing publications that users recognise and abide by the legal requirements associated with these rights.

- Users may download and print one copy of any publication from the public portal for the purpose of private study or research.

- You may not further distribute the material or use it for any profit-making activity or commercial gain

- You may freely distribute the URL identifying the publication in the public portal 
Efficient solution of the non-linear Reynolds equation for compressible fluid using the finite element method

\section{Jon S. Larsen \& Ilmar F. Santos}

Journal of the Brazilian Society of Mechanical Sciences and Engineering

ISSN 1678-5878

J Braz. Soc. Mech. Sci. Eng.

DOI 10.1007/s40430-014-0220-5
Journal of the Brazilian Society of

\section{Mechanical Sciences and Engineering}


Your article is protected by copyright and all rights are held exclusively by The Brazilian Society of Mechanical Sciences and Engineering. This e-offprint is for personal use only and shall not be self-archived in electronic repositories. If you wish to selfarchive your article, please use the accepted manuscript version for posting on your own website. You may further deposit the accepted manuscript version in any repository, provided it is only made publicly available 12 months after official publication or later and provided acknowledgement is given to the original source of publication and a link is inserted to the published article on Springer's website. The link must be accompanied by the following text: "The final publication is available at link.springer.com". 


\title{
Efficient solution of the non-linear Reynolds equation for compressible fluid using the finite element method
}

\author{
Jon S. Larsen • Ilmar F. Santos
}

Received: 6 January 2014 / Accepted: 6 July 2014

(C) The Brazilian Society of Mechanical Sciences and Engineering 2014

\begin{abstract}
An efficient finite element scheme for solving the non-linear Reynolds equation for compressible fluid coupled to compliant structures is presented. The method is general and fast and can be used in the analysis of airfoil bearings with simplified or complex foil structure models. To illustrate the computational performance, it is applied to the analysis of a compliant foil bearing modelled using the simple elastic foundation model. The model is derived and perturbed using complex notation. Top foil sagging effect is added to the bump foil compliance in terms of a close-form periodic function. For a foil bearing utilized in an industrial turbo compressor, the influence of boundary conditions and sagging on the pressure profile, shaft equilibrium position and dynamic coefficients is numerically simulated. The proposed scheme is faster, leading to the conclusion that it is suitable, not only for steady-state analysis, but also for non-linear time domain analysis of rotors supported by airfoil bearings.
\end{abstract}

Keywords Reynolds equation - Compressible fluid .

Finite element method

\section{List of Symbols}

$B_{\alpha \beta} \quad$ Damping coefficients, $\alpha \beta=x, y$

Technical Editor: Fernando Alves Rochinha.

J. S. Larsen $(\bowtie) \cdot$ I. F. Santos

Department of Mechanical Engineering, Technical University of

Denmark, DTU, Kongens Lyngby 2800, Denmark

e-mail: josla@mek.dtu.dk

I. F. Santos

e-mail: ifs@mek.dtu.dk

J. S. Larsen

Siemens A/S - Aeration Competence Center, Helsingør 3000,

Denmark

$\begin{array}{ll}C & \text { Radial clearance } \\ D & \text { Bearing diameter } \\ D & \text { Diffusion } \\ E & \text { Modulus of elasticity of foil } \\ K & \text { Foil flexibility } \\ K_{\mathrm{c}} & \text { Foil mobility } \\ K_{\alpha \beta} & \text { Stiffness coefficients, } \alpha \beta=x, y \\ L & \text { Bearing length } \\ N & \text { Shape function } \\ N_{\mathrm{p}} & \text { Number of pads } \\ R & \text { Journal radius } \\ S & \text { Bump foil pitch } \\ S & \text { Surface } \\ V & \text { Volume } \\ W_{x, y} & \text { Static load components } \\ f_{\gamma} & \text { Trigonometric functions } \\ \tilde{p}_{0} & \text { Approximating pressure } \\ b_{\text {foil }} & \text { Equivalent viscous damping of foil } \\ e_{x, y} & \text { Journal eccentricity components } \\ e_{x_{0}, y_{0}} & \text { Journal equilibrium position } \\ h & \text { Film height } \\ h_{0} & \text { Steady-state film height } \\ h_{\mathrm{c}} & \text { Film height correction } \\ h_{\mathrm{r}} & \text { Film height (rigid) } \\ l_{0} & \text { Bump half length } \\ p & \text { Pressure } \\ p_{0} & \text { Static pressure } \\ p_{\mathrm{a}} & \text { Ambient pressure } \\ p_{x}, p_{y} & \text { Perturbed pressures } \\ p_{\gamma} & \text { Dynamic pressure } \\ t & \text { Time } \\ t_{\mathrm{b}} & \text { Thickness of bump foil } \\ t_{\mathrm{t}} & \text { Thickness of top foil } \\ x, y, z & \text { Cartesian coordinates } \\ & \end{array}$


$\Delta e_{x, y} \quad$ Perturbation of journal equilibrium position

$\alpha \quad$ Convergence rate

$\beta \quad$ Relaxation factor for SUR

$\epsilon \quad$ Error

$\eta \quad$ Structural loss factor of foils

$\lambda$ Convergence factor

$\mu \quad$ Dynamic viscosity

$\nabla \cdot \quad$ Divergence

$\nabla \quad$ Gradient, $\nabla=\left\{\frac{\partial}{\partial \tilde{\theta}}, \frac{\partial}{\partial z}\right\}$

$v \quad$ Poisson's ratio of foil

$\omega \quad$ Angular speed of journal

$\omega_{\mathrm{s}} \quad$ Excitation frequency of journal

$\phi \quad$ Attitude angle

$\rho \quad$ Density

$\theta \quad$ Circumferential angle

$\theta_{l} \quad$ First pad leading edge angle

$\theta_{\mathrm{t}} \quad$ First pad trailing edge angle

$\tilde{\theta} \quad$ Circumferential coordinate, $\tilde{\theta}=\theta R$

$\varepsilon \quad$ Eccentricity ratio, $\varepsilon=\sqrt{e_{x}^{2}+e_{y}^{2}} / C$

$\varepsilon_{x}, \varepsilon_{y} \quad$ Eccentricity ratio

$\xi, \eta \quad$ Gauss points

$[B]$ Shape function derivatives matrix

$\left[K_{t}\right] \quad$ Tangential matrix

$[K] \quad$ Stiffness matrix

$[N] \quad$ Shape function matrix

$\left\{P_{0}\right\} \quad$ Static nodal pressure

$\left\{P_{\gamma}\right\} \quad$ Dynamic nodal pressure

$\{R\} \quad$ Residual vector

$\{U\} \quad$ Speed, $\{U\}=\{\omega R / 2,0\}^{T}$

$\{\mathbf{n}\} \quad$ Unit normal vector

$\{q\} \quad$ Right-hand side vector

\section{Introduction}

Gas bearings have been the subject for research within mechanical engineering for five decades [23]. Through the past three decades, compliant foil bearings (CFB) have found way into an increasing number of industrial applications within high-speed rotating machinery. The current tendency is, that the technology is progressing from small, high-speed rotating machinery, like dental drills and microturbines and specialized equipment related to the aeronautical industries, toward larger, mass-produced industrial compressors and turbines [8, 32]. In today's industrial compressors supported by CFB's, the assembled rotor weight is often above $50 \mathrm{~kg}$ and the rated power over $200 \mathrm{~kW}$. The advantages of these compressors compared to conventional oil-lubricated compressors are many, for instance low mechanical power loss, clean non-contaminating operation and the fundamental simplicity of the mechanical design. The main disadvantage of CFB's is related to their limited mechanical damping. Consequently, rotordynamic stability of CFB-supported compressors becomes a fundamental design issue. Though CFB's generally offer significantly better stability characteristics compared to rigid gas bearings, the stability of the rotor bearing system is still a major concern seen from an engineering perspective. As a result, much experimental and theoretical work has been conducted to achieve accurate mathematical models of the CFB dynamics.

Heshmat [9, 10] originally included the flexibility of the compliant foil implicitly in the Reynolds equation by introducing a linear elastic displacement as function of the fluid film pressure, $h_{\mathrm{c}}=K\left(p-p_{\mathrm{a}}\right)$. This simple elastic foundation model (SEFM) was extended by several authors $[12,15,24,25]$ to include a structural loss factor for the compliant foil and a perturbation method to obtain equations for the linearised stiffness and damping coefficients, which were solved by a finite difference scheme. San Andrés and Kim [30] later extended the model to include thermohydrodynamic effects (THD). Besides the theoretical work related to the SEFM, there has been many other significant contributions dealing with the complex behaviour of the compliant bump foil structures interacting with the housing surface [19, 20]. Highly worth mentioning is the work of Peng and Carpino [4], in which, detailed FE models of the compliant foil structure including equivalent frictional damping are coupled to the FE model of the lubrication film. In the attempt to couple complex structural FE models directly to the fluid film FE model, it is the authors' experience that there is a need for a fast converging and robust solution scheme.

In this paper, an efficient FE solution scheme based on the Newton-like (Nl) method [5] is introduced. Newton-like in the sense that it does not implement the true Jacobian. The solution scheme is applied to the SEFM but it is not limited to this model alone. It is suited for models including more detailed foil structure formulations as well. The method is compared to a standard iterative procedure, based on successive under relaxation (SUR). In this comparison, the SEFM is extended to include the effect of top foil sagging. Sagging occurs when the hydrodynamic film pressure causes a top foil deflection between bumps. The phenomenon was thoroughly investigated using both beam theory considerations [14] as well as analytical 2D plate theory [3, 21] and FE-based models [22, 28, 29, 34, 36]. Here, a periodic expression, based on simple beam theory, approximates the sagging effect analytically and is added to the foil flexibility originally given by Wallowit and Anno [31]. It is a closeform expression and allows for an arbitrary nodal discretization and makes numerical implementation straightforward compared to [14]. However, this expression is only valid for periodic bump foil distributions. 
The SEFM is perturbed using complex mathematical notation, enabling the introduction of a complex frequencydependant flexibility for the compliant foil structure, and FE formulations for the perturbed equations are derived. The zeroth-order FE equation is non-linear, and is solved using both SUR and the proposed Nl-based schemes. The two solution schemes are compared and the Nl-based scheme is found faster. The effective FE solution scheme constitutes the main original contribution of this work.

A Siemens foil bearing from an industrial compressor is analysed theoretically and the effect of the top foil sagging is investigated. Static and dynamic results from the analysis are presented for different sets of boundary conditions. While the actual time savings for the analysis presented are limited, the fast solution is still important in the case of a non-linear rotor simulation in time, where bearing forces need to be calculated between each time step. The method described in this paper was derived to be used for nonlinear analysis as well as to be extended by incorporating more complex foil structure models based on FEM [18]. Non-linear dynamic simulation tools applied to complex industrial rotors supported by CFB is still demanding faster numerical methods $[2,7,13,33,35]$.

\section{Theoretical model}

For a journal bearing with the nomenclature as given in Fig. 1a, the compressible Reynolds equation can be written in vector form [6] as

$\nabla \cdot\left(\frac{p h^{3}}{12 \mu} \nabla p\right)=\nabla \cdot(p h)\{U\}+\frac{\partial}{\partial t}(p h)$

where the film height $h(\theta, z, p)$ is defined as the film height of a rigid journal bearing $h_{r}(\theta)$, with the addition of a compliance, or deflection term $h_{\mathrm{c}}(p)=K\left(p-p_{\mathrm{a}}\right)$, which is dependant on the hydrodynamic pressure field and was first suggested by Heshmat [9]. The film height becomes

$h=h_{\mathrm{r}}+h_{\mathrm{c}}=C+e_{x} \cos (\theta)+e_{y} \sin (\theta)+K\left(p-p_{\mathrm{a}}\right)$

where $K$ is the structural flexibility related to the area of the compliant foil layers. With the notation defined in Fig. 1b, $K$ can be approximated as

$K(\tilde{\theta}) \approx \frac{S^{4}\left(1-v^{2}\right)}{E t_{\mathrm{t}}^{3}}\left(\frac{1}{60}-\frac{3}{2 \pi^{4}} \cos \left(\frac{2 \pi \tilde{\theta}}{S}\right)\right)+\frac{2 S}{E}\left(\frac{l_{0}}{t_{\mathrm{b}}}\right)^{3}\left(1-v^{2}\right)$

which is a superposition of the bump foil deflection given by Heshmat [9] and the top foil deflection given in Appendix 1. Expanding Reynolds Eq. (1) by inserting the

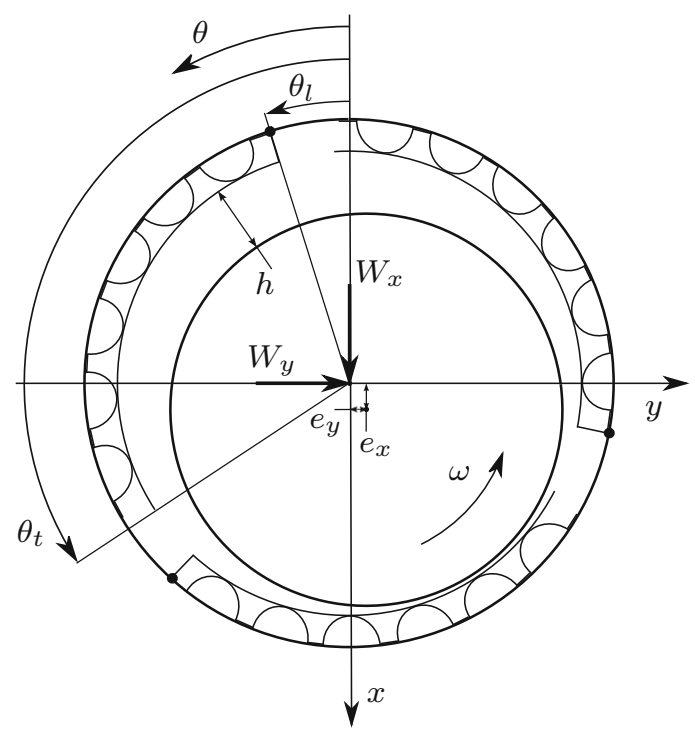

(a) Shaft and bearing.
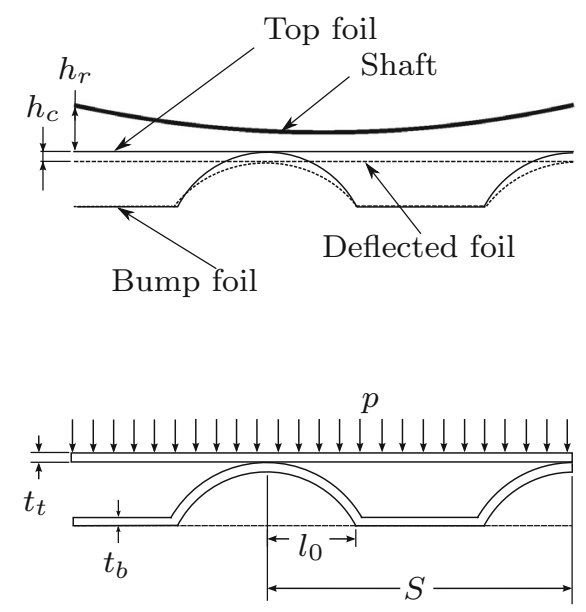

(b) Detailed view of bump and top foil.

Fig. 1 Schematics and nomenclature of a foil journal bearing with compliant outer surface

film height (2) leads to a modified Reynolds equation with the structural foil flexibility included implicitly

$$
\begin{aligned}
& \nabla \cdot\left(\frac{p h_{\mathrm{r}}^{3}}{12 \mu} \nabla p\right)+\nabla \cdot\left(\frac{p\left(p-p_{\mathrm{a}}\right)^{3} K^{3}}{12 \mu} \nabla p\right) \\
& \quad+\nabla \cdot\left(\frac{p h_{\mathrm{r}}\left(p-p_{\mathrm{a}}\right)^{2} K^{2}}{4 \mu} \nabla p\right) \\
& \quad+\nabla \cdot\left(\frac{p h_{\mathrm{r}}^{2}\left(p-p_{\mathrm{a}}\right) K}{4 \mu} \nabla p\right)=\nabla \cdot\left(p h_{\mathrm{r}}\right)\{U\} \\
& \quad+\nabla \cdot\left(p\left(p-p_{\mathrm{a}}\right) K\right)\{U\} \\
& \quad+\frac{\partial}{\partial t}\left(p h_{\mathrm{r}}\right)+\frac{\partial}{\partial t}\left(p\left(p-p_{\mathrm{a}}\right) K\right) .
\end{aligned}
$$




\subsection{Assumptions and limitations}

Solving this equation, for a given set of eccentricities $\left(e_{x}\right.$, $e_{y}$ ) and speed $\{U\}$, yields the hydrodynamic pressure $p$, in the fluid film, by implicitly taking into account the deformations in the compliant foil layers. In addition to the assumptions of laminar, Newtonian, thin-film flows, which together with the Navier-Stokes and the continuity equation leads to the Reynolds equation, the viscosity is assumed constant, i.e. isothermal condition. Furthermore, by including the foil flexibility in the radial direction as in (4), it is assumed that the foil radial stiffness is linear and that the radial deformation in any foil position $(\theta, z)$ is completely independent of the radial deformation in any neighbouring positions. Dependent on the particular foil configuration, bump geometry and top foil thickness, this may limit the validity of (4) and is discussed further in Sect. 3.3.

\subsection{Perturbed equations}

To investigate the dynamic performance of the bearing, a harmonic perturbation method is employed. The method, which was first introduced by Lund [23], is a commonly used and widely accepted method. Assuming that the shaft exhibits small harmonic oscillations around its equilibrium position in the bearing $\left(e_{x_{0}}, e_{y_{0}}\right)$, the shaft motion is given by

$e_{x}=e_{x_{0}}+\Delta e_{x} \mathrm{e}^{i \omega_{s} t}$ and $e_{y}=e_{y_{0}}+\Delta e_{y} \mathrm{e}^{i \omega_{s} t}$.

Assuming the amplitudes to be small $\Delta e_{x} \ll C$ and $\Delta e_{y} \ll C$, a first-order Taylor expansion of the pressure can be written as

$p=p_{0}+\left(\Delta e_{x} p_{x}+\Delta e_{y} p_{y}\right) \mathrm{e}^{i \omega_{s} t}$.

According to (6), the pressure $p$ is a harmonic oscillating field. This enables the introduction of a frequency-dependant mobility, in the film height function, rather than a static flexibility $K$. The mobility can be written as

$K_{\mathrm{c}}=K \frac{1-i \eta}{1+\eta^{2}}$

where $\eta=\omega_{s} b_{\text {foil }} K$ is the mechanical energy loss factor related to the foils [11]. Implementing the mobility $K_{\mathrm{c}}$, the film height becomes

$h=h_{\mathrm{r}}+h_{\mathrm{c}}=C+e_{x} \cos (\theta)+e_{y} \sin (\theta)+K_{\mathrm{c}}\left(p-p_{\mathrm{a}}\right)$.

Substituting (5), (6), (7) into (4) and (8), discarding secondand higher-order terms yields, upon separation of variables, the zeroth- and first-order equations:
Zeroth order

$\nabla \cdot\left(\frac{p_{0} h_{0}^{3}}{12 \mu} \nabla p_{0}\right)-\nabla \cdot\left(p_{0} h_{0}\right)\{U\}=\{0\}$

First order

$$
\begin{aligned}
\nabla & \cdot\left(\frac{p_{0} h_{0}^{3}}{12 \mu} \nabla p_{\gamma}\right)+\nabla \cdot\left(\frac{h_{0}^{3}+3 h_{0}^{2} p_{0} K_{\mathrm{c}}}{12 \mu} \nabla p_{0} p_{\gamma}\right) \\
& -\nabla \cdot\left(\left(h_{0}+p_{0} K_{\mathrm{c}}\right) p_{\gamma}\right)\{U\} \\
& -i \omega_{\mathrm{s}}\left(h_{0}+p_{0} K_{\mathrm{c}}\right) p_{\gamma}=-\nabla \cdot\left(\frac{p_{0} h_{0}^{2} f_{\gamma}}{4 \mu} \nabla p_{0}\right) \\
& +\nabla \cdot\left(p_{0} f_{\gamma}\right)\{U\}+i \omega_{\mathrm{s}}\left(p_{0} f_{\gamma}\right)
\end{aligned}
$$

where

$h_{0}=h_{r_{0}}+h_{c_{0}}=C+e_{x_{0}} \cos (\theta)+e_{y_{0}} \sin (\theta)+K_{c}\left(p_{0}-p_{\mathrm{a}}\right)$

and $\gamma=x, y$ and $f_{x}=\cos (\theta)$ and $f_{y}=\sin (\theta)$. Solving the zeroth-order Eq. (9) for an eccentricity $\left(e_{x_{0}}, e_{y_{0}}\right)$ and $\eta=0$ yields the static film pressure $p_{0}$. This pressure is then used when solving the first-order Eq. (10) to obtain the dynamic pressures $p_{x}$ and $p_{y}$. The bearing reaction forces are found by integration of the static pressure $p_{0}$ over the bearing surface

$\left\{\begin{array}{l}W_{x} \\ W_{y}\end{array}\right\}=-\int_{0}^{L} \int_{0}^{2 \pi}\left(p_{0}-p_{\mathrm{a}}\right)\left\{\begin{array}{l}\cos (\theta) \\ \sin (\theta)\end{array}\right\} R \mathrm{~d} \theta \mathrm{d} z$

and a similar integration of the dynamic pressures $\left(p_{x}, p_{y}\right)$ determines the dynamic stiffness and damping coefficients as

$$
\begin{aligned}
& {\left[\begin{array}{ll}
K_{x x} & K_{x y} \\
K_{y x} & K_{y y}
\end{array}\right]+i \omega_{\mathrm{s}}\left[\begin{array}{ll}
B_{x x} & B_{x y} \\
B_{y x} & B_{y y}
\end{array}\right]} \\
& \quad=\int_{0}^{L} \int_{0}^{2 \pi}\left[\begin{array}{lr}
p_{x} \cos (\theta) & p_{y} \cos (\theta) \\
p_{x} \sin (\theta) & p_{y} \sin (\theta)
\end{array}\right] R \mathrm{~d} \theta \mathrm{d} z .
\end{aligned}
$$

\section{Finite element formulation and solution}

The FE formulation is divided into two parts. The first part is dealing with the zeroth-order non-linear parabolic partial differential Eq. (9), for the static pressure $p_{0}$, which needs to be solved iteratively. The second part deals with the first-order linear complex differential Eq. (10), for the dynamic pressures $p_{\gamma}$, which can be solved directly.

While the first-order equation is easily solved, the solution of the zeroth-order equation is more complicated. Standard FE methods, like, e.g. the Bubnov-Galerkin method [5] could be employed to derive a system of equations of the form $\left[K\left(p_{0}\right)\right]\left\{p_{0}\right\}=\left\{q\left(p_{0}\right)\right\}$. The challenge in solving such a system for the pressure $\left\{p_{0}\right\}$ lies in the pressure dependency of the coefficient matrix $\left[K\left(p_{0}\right)\right]$ and the right-hand side $\left\{q\left(p_{0}\right)\right\}$. A straightforward method of overcoming this is to rewrite the system to an iterative form: 


$$
\left[K\left(p_{0_{i}}\right)\right]\left\{p_{0_{i+1}}\right\}=\left\{q\left(p_{0_{i}}\right)\right\} \text { for } i=1,2, \ldots
$$

which can be solved by consecutive updates of the pressure $\left\{p_{0_{i}}\right\}=\left\{p_{0_{i+1}}\right\}$ after each solution iteration $i$. However, this method will only converge for an extremely good starting guess of the initial pressure $\left\{p_{0_{1}}\right\}$. To improve the convergence, an SUR method of the form $p_{0_{i+1}}=\beta p_{0_{i}}+$ $(1-\beta) p_{0_{i-1}}$ where $\beta \in[0,1]$ can be applied. However, the relaxation factor $\beta$ needs to be very small to achieve convergence, meaning that the solution becomes slow, and often convergence is hardly achieved. To overcome this problem, an FE formulation which can be combined with the iterative Newton-Raphson solution scheme, as outlined in Appendix 2, is sought. The solution derived here, can be seen as the equivalent to solving structural problems including material non-linearities $[5,16]$. The procedure can be used on not only the SEFM, but also in combination with more complex mathematical models including detailed foil structure formulations.

\subsection{Zeroth-order equation}

A Bubnov-Galerkin FE procedure with implementation of an isoparametric element formulation is followed [5]. First (9) is rewritten into the compact form as

$$
\nabla \cdot\left(D \nabla p_{0}\right)=\nabla \cdot\left(p_{0} h\right)\{U\}
$$

where the diffusion coefficient $D\left(p_{0}\right)=\frac{p_{0} h^{3}}{12 \mu}$ is a scalar and real field (only the real part of the foil mobility is used in the zeroth-order equation). Second, an approximating pressure field $\tilde{p}_{0}=[N]\left\{p_{0}^{e}\right\}$ over an element is introduced, where $\left\{p_{0}^{e}\right\}$ is the nodal pressure and $[N]$ is the shape function matrix. Thus the Galerkin residual equation for (15), on the element level, is

$$
\int_{V^{e}}[N]^{T} \nabla \cdot\left(D \nabla \tilde{p}_{0}\right) \mathrm{d} V-\int_{V^{e}}[N]^{T} \nabla \cdot\left(\tilde{p}_{0} h\right)\{U\} \mathrm{d} V=\{0\}
$$

where $V^{e}$ is the element volume. Applying Green's theorem on (16) yields

$$
\begin{aligned}
& -\int_{V^{e}}[B]^{T}\left(D \nabla \tilde{p}_{0}\right) \mathrm{d} V+\int_{S^{e}}[N]^{T}\left(D \nabla \tilde{p}_{0}\right)\{\mathbf{n}\} \mathrm{d} S \\
& +\int_{V^{e}}[B]^{T}\left(\tilde{p}_{0} h\right)\{U\} \mathrm{d} V-\int_{S^{e}}[N]^{T}\left(\tilde{p}_{0} h\right)\{U\}\{\mathbf{n}\} \mathrm{d} S=\{0\}
\end{aligned}
$$

where matrix $[B]^{T}=\left[[N, \tilde{\theta}]^{T}[N, z]^{T}\right]$ contains the spatial derivatives of the shape functions and $\{\mathbf{n}\}$ is the outward pointing unit normal vector of surface element $\mathrm{d} S$. Due to continuity conditions, the boundary integrals vanishes and (17) reduces to
$\int_{V^{e}}[B]^{T} D \nabla \tilde{p}_{0} \mathrm{~d} V-\int_{V^{e}}[B]^{T} \tilde{p}_{0} h\{U\} \mathrm{d} V=\{0\}$.

The spatial derivatives of the approximating pressure field are $\tilde{p}_{0, i}=[N, i]\left\{p_{0}^{e}\right\}$ with $i=\tilde{\theta}, z$ or in vector form, $\nabla \tilde{p}_{0}=[B]\left\{p_{0}^{e}\right\}$. Inserting this into (18) gives

$$
\begin{aligned}
\left\{R^{e}\right\}= & \left\{R_{\mathrm{ext}}^{e}\right\}-\left\{R_{\mathrm{int}}^{e}\right\}=\{0\}-\int_{V^{e}}[B]^{T} D[B]\left\{p_{0}^{e}\right\} \mathrm{d} V \\
& +\int_{V^{e}}[B]^{T}\{U\} h[N]\left\{p_{0}^{e}\right\} \mathrm{d} V
\end{aligned}
$$

where $\left\{R_{\text {int }}^{e}\right\}$ and $\left\{R_{\text {ext }}^{e}\right\}$ are the internal and external residuals. The tangent matrix on element level [16] is then:

$$
\left[K_{\mathrm{t}}^{e}\right]=\frac{\partial\left\{R_{\text {int }}^{e}\right\}}{\partial\left\{p_{0}^{e}\right\}}=\int_{V^{e}}[B]^{T} D[B] \mathrm{d} V-\int_{V^{e}}[N]^{T}\{U\}^{T} h[B] \mathrm{d} V .
$$

It is important to highlight that Newton's method, or the frequently called Newton-Raphson method in the engineering is second-order accurate when: (a) the true Jacobian is used, for example, obtained explicitly from the set of non-linear equations and (b) the solution of the linearised systems of equations is obtained to machine precision. In this framework, the procedure presented here only satisfies (b) since $D$ was kept constant when taking the derivative $\partial\left\{R_{\text {int }}^{e}\right\} / \partial\left\{p_{0}^{e}\right\}$. Being strictly rigorous, hereby (15) is solved using a 'Newton-like' procedure, since the true Jacobian is not used.

The element vectors and matrices are expanded to structure size by the usual element summation:

$$
\left[K_{\mathrm{t}}\right]=\sum_{e}\left[K_{t}^{e}\right] ; \quad\{R\}=\sum_{e}\left\{R^{e}\right\} ; \quad\{p\}=\sum_{e}\left\{p^{e}\right\}
$$

where the volume integrals are numerically integrated using a quadrature rule [5]. The scalar field quantities $p_{0}, h$, $K_{\mathrm{c}}$ in $D$ are calculated in the respective Gauss points $\left(\xi_{i}, \eta_{j}\right)$ using the interpolation functions as:

$$
q\left(\xi_{i}, \eta_{j}\right)=\left[N\left(\xi_{i}, \eta_{j}\right)\right]\left\{q^{e}\right\}
$$

where $q$ and $\left\{q^{e}\right\}$ are the scalar field quantities and nodal vectors, respectively. Full integration must be employed, which in case of linear four-node quadrilateral elements (Q4) means that 2 by 2 Gauss points are used. An algorithm for implementing the Nl scheme (as outlined in Appendix 2) is given as a pseudocode in Appendix 3. The Nl scheme provides the solution $p_{0}$ for a given set of eccentricities $\left(e_{x_{0}}, e_{y_{0}}\right)$. Upon integration of $p_{0}$, using (12), a set of reaction forces $\left(W_{x}, W_{y}\right)$ is obtained which needs to be balanced with the prescribed bearing loads. This force/reaction balance is established iteratively using common root finding 
algorithms, e.g. the Newton-Raphson method for systems of equations. During this step, the film height $h$ is updated in $\left[K_{t}\right]$ and $\{R\}$ based on (8). In contrary to the SEFM, $h$ might also be updated by means of a more complex formulation of the foil structure, e.g. a non-linear FE model.

\subsection{First-order equation}

The first-order Eq. (10) is a linear complex differential equation. Following the same Bubnov-Galerkin FE procedure as for the zeroth-order equation leads to a linear set of complex algebraic equations

$$
\left[K_{\gamma}\right]\left\{p_{\gamma}\right\}=\left\{q_{\gamma}\right\}
$$

which can be solved by factorization for the dynamic pressures. The coefficient matrix $\left[K_{\gamma}\right]$ and right-hand side $\left\{q_{\gamma}\right\}$ on the element level are given by

$$
\begin{aligned}
{\left[K_{\gamma}^{e}\right]=} & \int_{V^{e}}\left([B]^{T} C_{1}[B]+[B]^{T} C_{2}[B]\left\{p_{0}\right\}[N]+[B]^{T} C_{4}\{U\}[N]\right. \\
& \left.-[N]^{T} i \omega_{\mathrm{s}} C_{4}[N]\right) \mathrm{d} V \\
\left\{q_{\gamma}^{e}\right\}= & \int_{V^{e}}\left([B]^{T} C_{3} f_{\gamma}[B]\left\{p_{0}\right\}+[B]^{T} p_{0} f_{\gamma}\{U\}-i \omega_{\mathrm{s}} p_{0} f_{\gamma}[N]^{T}\right) \mathrm{d} V
\end{aligned}
$$

where the coefficients are

$$
\begin{aligned}
& C_{1}=\frac{p_{0} h_{0}^{3}}{12 \mu} \\
& C_{2}=\frac{h_{0}^{3}+3 h_{0}^{2} p_{0} K_{\mathrm{c}}}{12 \mu} \\
& C_{3}=-\frac{p_{0} h_{0}^{2}}{4 \mu} \\
& C_{4}=-\left(h_{0}+p_{0} K_{\mathrm{c}}\right) .
\end{aligned}
$$

During the numerical integration procedure of the coefficient matrix and right-hand side vector (24), all field quantities are calculated in the Gauss points using the shape functions.

\subsection{Mesh and boundary conditions}

The boundary conditions for the zeroth- and first-order systems (19), (20), (23), are applied following the common methods. For a compliant foil bearing as depicted in Fig. 1a, the boundary conditions are

$$
\begin{aligned}
& p_{0}:\left\{\begin{array}{l}
p_{0}\left(\theta_{l}, z\right)=p_{0}\left(\theta_{\mathrm{t}}, z\right)=p_{\mathrm{a}} \\
p_{0}(\theta, L / 2)=p_{0}(\theta,-L / 2)=p_{\mathrm{a}}
\end{array}\right. \\
& p_{\gamma}:\left\{\begin{array}{l}
p_{\gamma}\left(\theta_{l}, z\right)=p_{\gamma}\left(\theta_{\mathrm{t}}, z\right)=0 \\
p_{\gamma}(\theta, L / 2)=p_{\gamma}(\theta,-L / 2)=0 .
\end{array}\right.
\end{aligned}
$$

The boundary condition for the zeroth-order equation of $p_{0}$ is implemented in the solution algorithm, as outlined in
Appendix 3. In short, it should only be applied for the first iteration of the solution. The boundary condition for the first-order equation of $p_{\gamma}$ is prescribed by standard FE techniques.

As illustrated in Fig. 2, the prescribed boundary conditions (26) will pose a problem for large journal eccentricities. The foil deflection $h_{\mathrm{c}}\left(p_{0}\right)=K_{\mathrm{c}}\left(p_{0}-p_{\mathrm{a}}\right)$ becomes zero in the nodes where $p_{0}=p_{\mathrm{a}}$. This is the case on the pad edges. If the bearing pad mesh in Fig. 2a is subjected to ambient pressure $p_{\mathrm{a}}$ on its left edge and the bearing eccentricity ratio is approaching 1, the resulting film height $h$ and the deflected pad profile will take a form as illustrated in Fig. $2 b$ (Standard $\mathrm{BC})$. This is obviously incorrect, since the radial deflection of the top foil along the axial direction $z$ should be smooth. In the situation illustrated, with zero film height $h$ on the edge, the air leakage will become zero with an elevated pressure along the edge as a consequence. This is a problem specifically related to the SEFM. To correct it, one has to assure that the foils take on realistic deflections on the pad edges. This can be achieved by meshing with a narrow band of elements, having the width of $L / 50$ or less, along the bearing edges subjected to ambient pressure and letting the foil deflection $h_{\mathrm{c}}(p)$ in the outermost nodes of these elements (on the bearing edge), adopt the deflection values of the innermost nodes (away from the bearing edge) on that element. This situation is shown in Fig. 2b (BC1).

For foil configurations where the top foil is stiffer than the bump foil, the top foil deflection can be regarded as constant along the axial direction of the bearing [26]. In these cases, the deflection $h_{\mathrm{c}}\left(p_{\mathrm{m}}\right)$ can be used where the pressure $p_{\mathrm{m}}$ is taken as the arithmetic mean pressure along the axial direction for a given angle $\theta$. This situation is illustrated in Fig. 2b (BC2).

In gas bearings, where the fluid is compressible, significant sub-ambient pressures may arise. These subambient pressures will cause the top foil to separate from the bumps into a position in which the pressure on both sides of the pad is equalized. Heshmat [10] introduced a set of boundary conditions accounting for this separation effect. However, in this work, a simple Gümbel [6] boundary condition is imposed, which means that subambient pressures are discarded when integrating the pressure to obtain the bearing force components $\left(W_{x}, W_{y}\right)$. This means that the parts of the bearing having subambient pressures are inactivated and hence these areas need prescribed boundary conditions, $p_{\gamma}=0$ where $p_{0}<p_{\mathrm{a}}$, when solving the first-order equation.

\subsection{Numerical implementation}

The foil flexibility $K(\theta)$ is a periodic expression (3) in the circumferential direction, it is therefore important to define 


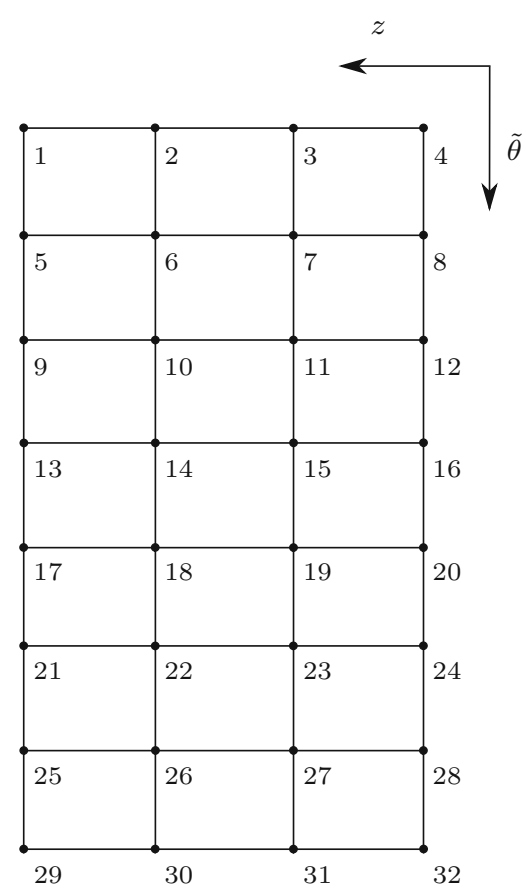

(a) FE mesh of a single pad.
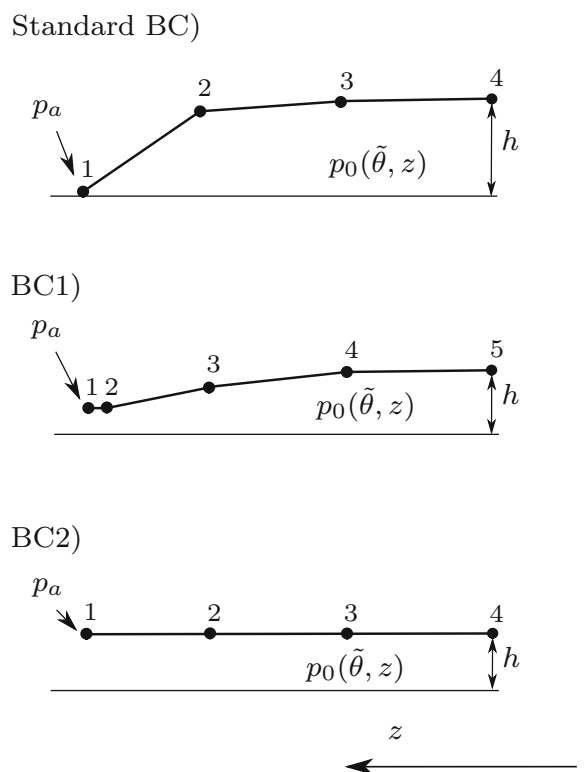

(b) Film height and pad deflection along axial direction.

Fig. 2 Schematics of FE mesh for a single pad and the effect of boundary conditions on its edges

an FE mesh having a sufficient number of element divisions in $\theta$, to avoid aliasing which may lead to significant errors in the pressure solution. This means a minimum of two element divisions per bump is required. In practice, a larger number may be desirable to obtain an accurate solution of the pressure field $p_{0}(\theta, z)$. The adequate number of element divisions should be determined from case to case by a mesh convergence study. Dependent on the amount of top foil sagging a smaller or larger amount of element divisions may be necessary.

To improve convergence of the outer Newton-Raphson scheme, which balances the bearing loads $\left(W_{x}, W_{y}\right)$ with the pressure $p_{0}\left(e_{x}, e_{y}\right)$, the integration of the pressure (12) should preferably be carried out by an accurate integration algorithm. Good results are obtained using a modified Simpson algorithm, modified to cope with uneven nodal spacing and both equal and odd number of element divisions. An accurate integration of the dynamic pressure $p_{\gamma}$ will improve the accuracy of the calculated bearing coefficients (13) as well.

The coefficient matrices of both the zeroth- and firstorder systems, $\left[K_{\mathrm{t}}\right]$ and $\left[K_{\gamma}\right]$, are banded. This feature should be exploited by utilizing a sparse matrix storage format and a sparse solver. In the current implementation, the LAPACK dgbsv solver is used [1].

\subsection{Performance}

The performance of the Nl solution scheme, for solving the zeroth-order equation, outlined in Sect. 3.1 and Appendix 2, is compared to the SUR scheme. For this comparison, a single pad bearing often referred to in the literature [27], is analysed and the static shaft equilibrium position and film pressure profile is calculated. To investigate how the foil flexibility $h_{\mathrm{c}}=K\left(p_{0}-p_{\mathrm{a}}\right)$ affects the convergence of the two methods, both a rigid $\left(h_{\mathrm{c}}=0\right)$ version and a flexible $\left(h_{\mathrm{c}} \neq 0\right)$ version of the bearing are analysed. The geometry of the bearing is outlined in Table 1 .

A relaxation factor of $\beta=0.1$ is used with the SUR solution. This value is found to be near optimal for the given bearing and operating conditions. Using a starting guess for the eccentricity $\left(\varepsilon_{x}, \varepsilon_{y}\right)=(0.3,0.3)$, the BC1 and no Gumbel boundary condition, the solution converges to the equilibrium positions $\left(\varepsilon_{x_{0}}, \varepsilon_{y_{0}}\right)=(0.62,0.42)$ with foil flexibility included and $\left(\varepsilon_{x_{0}}, \varepsilon_{y_{0}}\right)=(0.36,0.39)$ when foil flexibility is neglected $\left(h_{\mathrm{c}} \neq 0\right)$. The convergence, in terms of the Euclidean norm of the pressure difference between consecutive iterations, is illustrated in Fig. 3 for each of the four cases.

For all cases, a mesh consisting of 594 elements and 670 nodes is used. Refining the mesh is not found to change pressure convergence. It is clear from Fig. 3, that the Nl solutions converge faster than the SUR solutions. In this example, the iterations are stopped when $\left\|\left\{p_{i+1}\right\}-\left\{p_{i}\right\}\right\|<1$. However, the convergence criteria of the $\mathrm{Nl}$ method is normally based on the residual (19), such that convergence is obtained when $\|\{R\}\|<10^{-6}$.

To evaluate the convergence, the error $\epsilon$ between two consecutive iterations is assumed to follow the relation [5] 
Table 1 Geometry, material properties and operating conditions of a single pad foil bearing

\begin{tabular}{ll}
\hline Parameters & Values \\
\hline Bearing radius $(R)$ & $19.05 \mathrm{~mm}$ \\
Bearing length $(L)$ & $38.10 \mathrm{~mm}$ \\
Bearing clearance $(C)$ & $32 \mu \mathrm{m}$ \\
Bump foil thickness $\left(t_{\mathrm{b}}\right)$ & $0.1016 \mathrm{~mm}$ \\
Top foil thickness $\left(t_{\mathrm{t}}\right)$ & $0.2032 \mathrm{~mm}$ \\
Bump foil pitch $(S)$ & $4.572 \mathrm{~mm}$ \\
Bump half length $\left(l_{0}\right)$ & $1.778 \mathrm{~mm}$ \\
Young's modulus of bump foil $(E)$ & $2.07 \times 10^{-11} \mathrm{~Pa}$ \\
Poisson's ratio of bump foil $(v)$ & 0.3 \\
Loss factor $(\eta)$ & 0.25 \\
Ambient pressure $\left(P_{\mathrm{a}}\right)$ & $1 \times 10^{-5} \mathrm{~Pa}$ \\
Air viscosity $(\mu)$ & $95 \times 10^{-5} \mathrm{~Pa} \cdot \mathrm{s}$ \\
Air density $(\rho)$ & $1.06 \mathrm{~kg} \mathrm{~m}$ \\
Load $\left[\left(W_{x}, W_{y}\right)\right]$ & $(50,0) \mathrm{N}$ \\
Speed $(\omega)$ & $40,000 \mathrm{RPM}$ \\
\hline
\end{tabular}

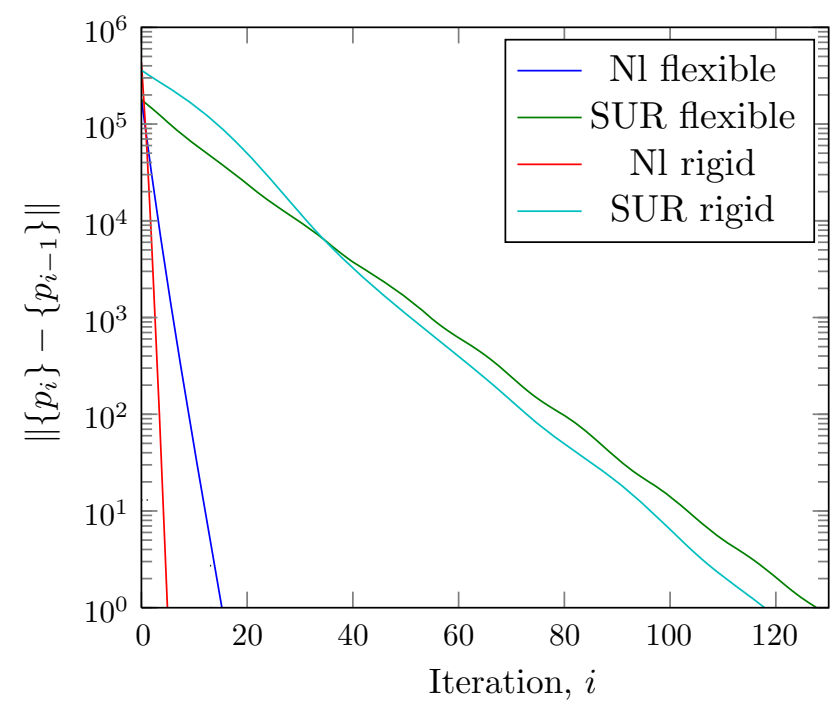

Fig. 3 Pressure convergence for the first eccentricity step. Successive under relaxation with a factor $\beta=0.1$ compared to the Newton-like method for flexible and rigid bearings

$\epsilon_{i+1}=\lambda \epsilon_{i}^{\alpha}$

where $\alpha$ is the rate of convergence and $\lambda$ is the convergence factor. If the ratio of consecutive errors is approximated by the ratio of consecutive differences as

$\frac{\epsilon_{i+1}}{\epsilon_{i}} \approx \frac{\left\|\left\{p_{i+1}\right\}-\left\{p_{i}\right\}\right\|}{\left\|\left\{p_{i}\right\}-\left\{p_{i-1}\right\}\right\|}$

then the convergence rate $\alpha$ can be estimated as

$\alpha \approx \frac{\log \left(\left\|\left\{p_{i+1}\right\}-\left\{p_{i}\right\}\right\| /\left\|\left\{p_{i}\right\}-\left\{p_{i-1}\right\}\right\|\right)}{\log \left(\left\|\left\{p_{i}\right\}-\left\{p_{i-1}\right\}\right\| /\left\|\left\{p_{i-1}\right\}-\left\{p_{i-2}\right\}\right\|\right)}$
Table 2 Estimated convergence rate and factor for each calculation case

\begin{tabular}{lll}
\hline Case & $\alpha$ & $\lambda$ \\
\hline Nl flexible & 1.0 & 0.52 \\
SUR flexible & 1.0 & 0.94 \\
Nl rigid & 1.1 & 0.04 \\
SUR rigid & 1.0 & 0.90 \\
\hline
\end{tabular}

The values are averaged over all iterations

and the convergence factor $\lambda$ can be estimated by:

$\lambda \approx \frac{\left\|\left\{p_{i+1}\right\}-\left\{p_{i}\right\}\right\|}{\left\|\left\{p_{i}\right\}-\left\{p_{i-1}\right\}\right\|^{\alpha}}$.

In Table 2 the convergence rates and factors for the four cases, estimated by (29) and (30), are listed.

The convergence rate is found to be $\alpha=1.1$ for the $\mathrm{Nl}$ solution of the rigid bearing and $\alpha=1$ for all other cases. This is far from second-order convergence $(\alpha=2)$ which is theoretically obtainable with the Newton-Raphson method. When taking the derivative of the residual $\left\{R_{\mathrm{i}}\right\}$ to obtain the tangential matrix $\left[K_{\mathrm{t}}\right]$ in (20), the diffusion coefficient $D$ is kept constant. In fact it is not constant but updated between each iteration, hence the full Jacobian is not obtained. However, the Nl solutions are found to have lower convergence factors $\lambda$ than the SUR solutions which explains the faster convergence. For both schemes, a pressure equilibrium iteration is equivalent to inverting the coefficient matrix $[K]$ or $\left[K_{\mathrm{t}}\right]$ which in this example corresponds to solving a system of 670 linear equations per pressure iteration $i$.

\section{Analysis of industrial foil bearing}

The static results of the SEFM, i.e. pressure profile, film height, eccentricity ratio have been compared and validated to experimental results in [17]. Here, the pressure profiles, equilibrium position and the stiffness and damping coefficients are calculated theoretically.

The investigated bearing is that of a Siemens directdriven compressor with the geometry and material properties as outlined in Table 3. The real bearing has a top foil thickness $t_{\mathrm{t}}$ of twice the value given in the table, but to exaggerate the sagging effect, only half the real thickness is used in the calculation. The bearing is subjected to loads $W_{x}=115 \mathrm{~N}, \quad W_{y}=0$ and the shaft is rotated at $\omega=15.000$ RPM. A total of four different cases has been investigated. Each of these cases involves a different set of boundary conditions outlined in Table 4 together with the calculated eccentricity ratio $\varepsilon$. Based on a mesh convergence analysis, as illustrated in Fig. 4, a grid of 9 elements over the length and 88 elements in circumferential 
Table 3 Geometry, material properties and operating conditions of the Siemens airfoil bearing

\begin{tabular}{ll}
\hline Parameters & Values \\
\hline Bearing radius $(R)$ & $50.00 \mathrm{~mm}$ \\
Bearing length $(L)$ & $78.00 \mathrm{~mm}$ \\
Bearing clearance $(C)$ & $70 \mu \mathrm{m}$ \\
Number of pads $\left(N_{\mathrm{p}}\right)$ & 3 \\
First pad leading edge $\left(\theta_{\mathrm{l}}\right)$ & $30^{\circ}$ \\
First pad trailing edge $\left(\theta_{\mathrm{t}}\right)$ & $145^{\circ}$ \\
Bump foil thickness $\left(t_{\mathrm{b}}\right)$ & $0.127 \mathrm{~mm}$ \\
Top foil thickness $\left(t_{\mathrm{t}}\right)$ & $0.127 \mathrm{~mm}$ \\
Bump foil pitch $(S)$ & $7.00 \mathrm{~mm}$ \\
Bump half length $\left(l_{0}\right)$ & $3.30 \mathrm{~mm}$ \\
Young's modulus of bump foil $(E)$ & $2.07 \times 10^{11} \mathrm{~Pa}$ \\
Poisson's ratio of bump foil $(v)$ & 0.3 \\
Loss factor $(\eta)$ & 0.25 \\
Ambient pressure $\left(P_{\mathrm{a}}\right)$ & $1 \times 10^{5} \mathrm{~Pa}$ \\
Air viscosity $(\mu)$ & $1.95 \times 10^{-5} \mathrm{~Pa} \cdot \mathrm{s}$ \\
Air density $(\rho)$ & $1.06 \mathrm{~kg} \mathrm{~m}{ }^{-3}$ \\
\hline
\end{tabular}

direction per pad amounting to 2,670 nodes are used for all cases. The low number of elements over the length of the bearing is achieved by exploiting the symmetry around $z=L / 2$.The eccentricity ratio is found to be nearly constant for the four different cases. The tendency is that the eccentricity ratio increases slightly by including the sagging effect. Similarly, the eccentricity ratio is slightly higher when using $\mathrm{BC} 1$ compared to $\mathrm{BC} 2$. This makes sense since $\mathrm{BC} 1$ allows for an uneven foil deflection along the length of the bearing. Overall, the effect of the boundary conditions on the eccentricity ratio is regarded as negligible for this medium loaded bearing. Previous results [17] showed that the two boundary conditions have a significant effect on the shape of the film pressure profiles. It was found that the $\mathrm{BC} 1$ resulted in an almost flat pressure distribution along the length of the bearing and $\mathrm{BC} 2$ gave a more pointed pressure with a slightly higher maximum. In Figs. 5 and 6 , the pressure profiles for case 1 and 2 using the $\mathrm{BC} 2$ are illustrated. Comparing these, it is clear that the maximum pressure $p / p_{\mathrm{a}}=1.35$ is the same for both cases but the shape of the pressure profile is altered for the second case, where the sagging effect is included. The sagging clearly alters the pressure profile, especially on the second pad where the pressures are highest.

The stiffness and damping coefficients of the bearing are calculated for all four cases in a range of excitation frequencies $\omega_{s} / \omega=[0.1 ; 100]$. The results are illustrated in Fig. 7. Due to the compressibility of the lubricant, both the stiffness and damping are highly frequency dependant. It is observed that the direct stiffness $K_{x x}$ in the load direction is slightly dependant on the boundary conditions imposed on
Table 4 Boundary conditions and calculated eccentricities for the four cases under investigation

\begin{tabular}{lllll}
\hline $\begin{array}{l}\text { Case } \\
\text { edges }\end{array}$ & $\begin{array}{l}\text { B.C. on } \\
\text { separation }\end{array}$ & $\begin{array}{l}\text { Foil } \\
\text { sagging }\end{array}$ & $\begin{array}{l}\text { Eccentricity } \\
\text { ratio, } \varepsilon\end{array}$ \\
\hline 1 & BC2 & Gumbel b.c. & Excluded & 1.218 \\
2 & BC2 & Gumbel b.c. & Included & 1.264 \\
3 & BC1 & Gumbel b.c. & Excluded & 1.224 \\
4 & BC1 & Gumbel b.c. & Included & 1.262 \\
\hline
\end{tabular}

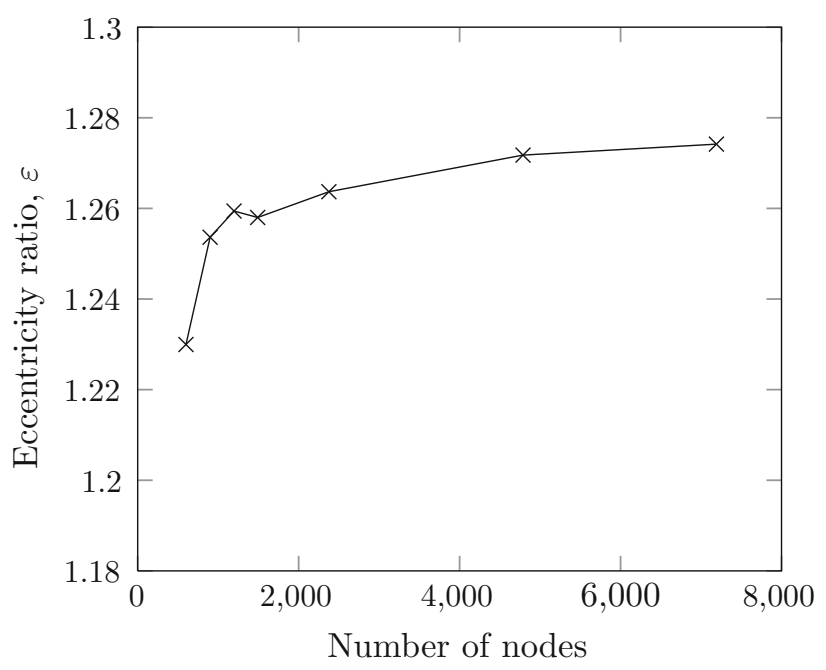

Fig. 4 Mesh convergence curve-calculated eccentricity ratio at different mesh sizes for Case 2

the pad edges (BC1 vs. BC2). However, the effect of including the sagging effect is regarded as being insignificant.

For the above analysis, the zeroth-order non-linear equation was solved using both the SUR method and the proposed Nl solution scheme. Again, a speed up of approximately a factor 10 was seen for the $\mathrm{Nl}$ solution scheme.

\section{Conclusions and future aspects}

Two solutions of the non-linear Reynolds equation for compressible fluids were compared. One based on an iterative Nl method, and one based on a SUR solution scheme. Both methods were found to have convergence rates close to 1 . Even though the $\mathrm{Nl}$ method did not achieve a convergence rate of 2 , i.e. second-order convergence, it had a lower convergence factor and converged nearly 10 times faster than the SUR method for a flexible bearing and more than 20 times faster for a rigid bearing.

Two different sets of boundary conditions which deal with the lack of foil deflection on the edges subjected to 
Fig. 5 Pressure field for the Siemens 3 pad foil bearing calculated for a bearing clearance and load of $C=70 \mu \mathrm{m}$ and $W_{x}=115 \mathrm{~N}$. Sagging effect of top foil neglected (mesh size reduced for illustration purpose)

Fig. 6 Pressure field for the Siemens 3 pad foil bearing calculated for a bearing clearance and load of $C=70 \mu \mathrm{m}$ and $W_{x}=115 \mathrm{~N}$. Sagging effect of top foil included (mesh size reduced for illustration purpose)
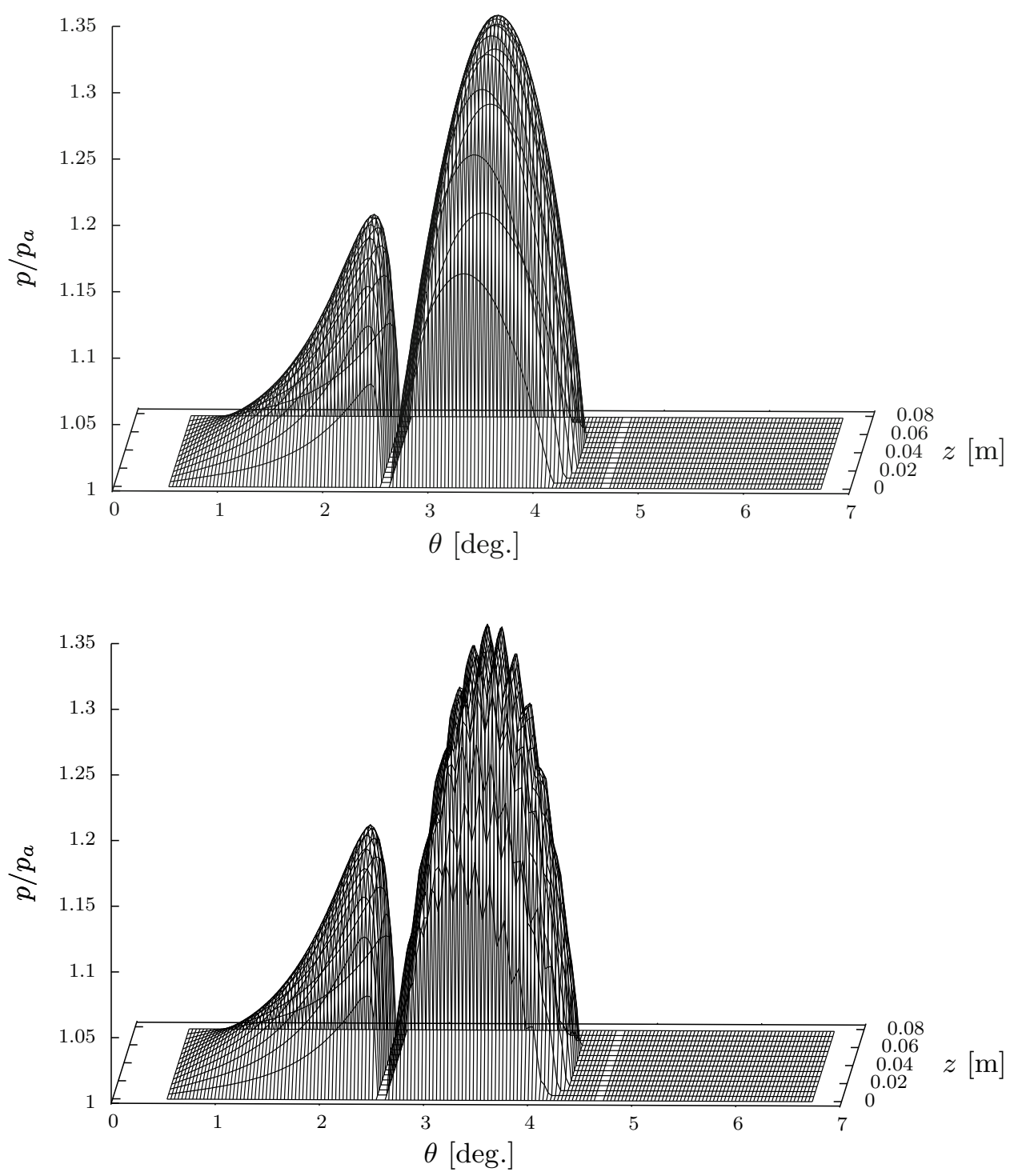

ambient pressure were investigated for a medium loaded bearing. Switching between the two different boundary conditions, $\mathrm{BC} 1$ and $\mathrm{BC} 2$, yields slightly different pressure profiles, but the shaft equilibrium position changes by less than $1 \%$. The influence on the dynamic stiffness and damping coefficients was found to be insignificant.

Finally, the inclusion of the top foil sagging effect was investigated. It was found that the foil sagging on a medium loaded bearing does not significantly affect the equilibrium position, which stays within $4 \%$ of the value obtained without the sagging effect included. Furthermore, the dynamic stiffness and damping coefficients were not found to be significantly affected by the sagging effect.

The mathematical model (SEFM) and solution scheme outlined in this paper can easily be extended to incorporate tabulated experimental values of the foil flexibility and damping, considering them constant or frequency dependent. Furthermore, the scheme is suitable for simulating non-linear rotor bearing systems in time due to the improved convergence.

\section{Appendix 1: Top foil deflection}

To include the 'sagging' effect of the top foil, as illustrated in Fig. 8a, into the mathematical model of the foil bearing, a periodic expression for the top foil flexibility, dependant on the angle $\theta$, is sought. If the top foil is assumed to have unit width, the uniform pressure $P$ becomes a uniformly distributed load along $x$ (Fig. 8b). The top foil is assumed in pure bending and the bump foil deflection is kept at zero. Requiring the infinitesimal element of the top foil, Fig. 8b, to be in static equilibrium one obtain: 
Fig. 7 Calculated stiffness and damping coefficients for the Siemens foil bearing. Case 1 blue, Case 2 red, Case 3 green, Case 4 magenta
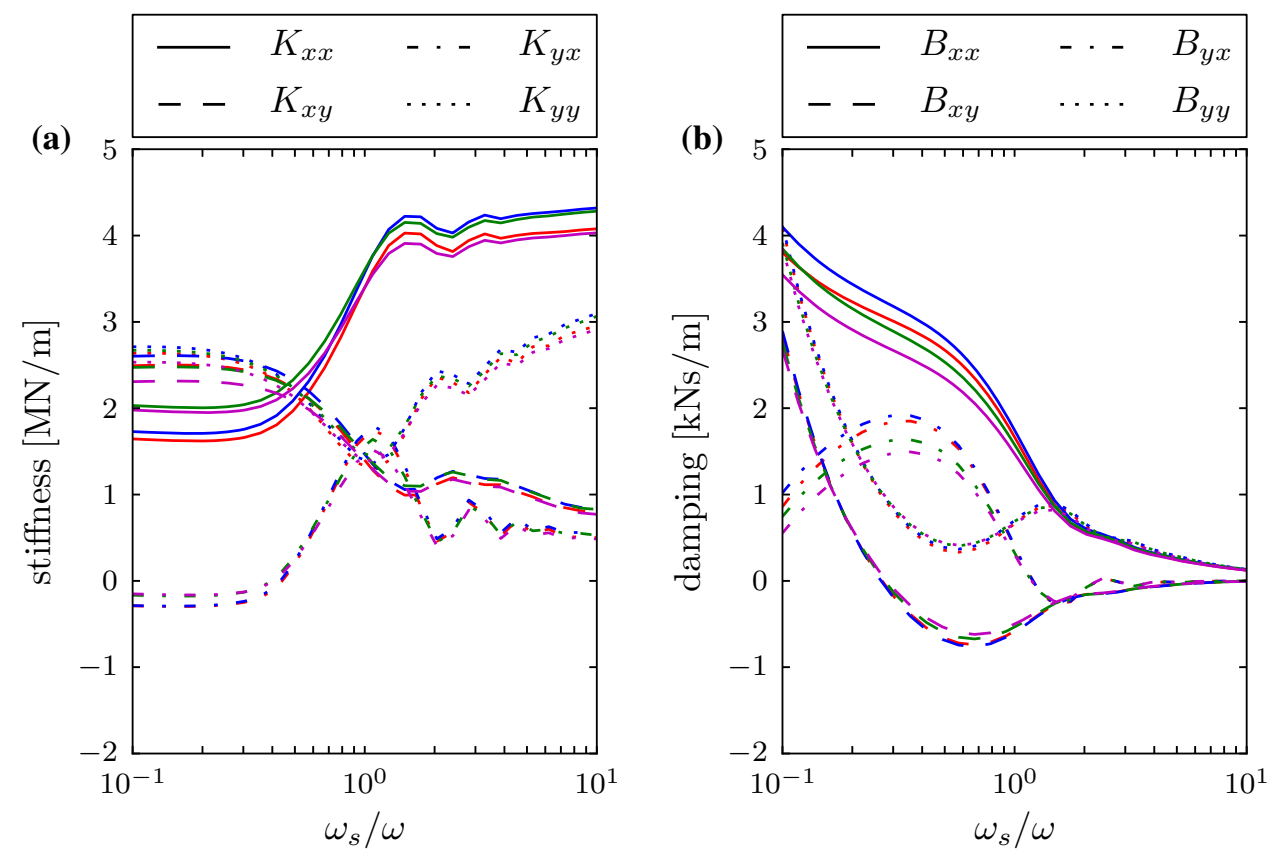

$M+\mathrm{d} M-M+\frac{1}{2} P \mathrm{~d} \tilde{\theta}^{2}+(T+\mathrm{d} T) \mathrm{d} \tilde{\theta}=0 \quad \Rightarrow \frac{\mathrm{d} M}{d \tilde{\theta}}=T$

$-N+N+\mathrm{d} N=0 \quad \Rightarrow \mathrm{d} N=0$

$T+\mathrm{d} T-T-P \mathrm{~d} \tilde{\theta}=0 \quad \Rightarrow \frac{\mathrm{d} T}{\mathrm{~d} \tilde{\theta}}=P$

rewriting and differentiating (31) yields

$\frac{\mathrm{d} M}{\mathrm{~d} \tilde{\theta}}=T \Rightarrow \frac{\mathrm{d}^{2} M}{\mathrm{~d} \tilde{\theta}^{2}}=\frac{\mathrm{d} T}{\mathrm{~d} \tilde{\theta}}=P$.

If pure bending in one direction is assumed, then Kirchhoff-Love plate theory for isotropic plates, describes the relation between the bending moment $M$ and the curvature $\frac{\mathrm{d}^{2} w_{t}}{\mathrm{~d} \tilde{\theta}^{2}}$ as

$M=D_{t} \frac{\mathrm{d}^{2} w_{t}}{\mathrm{~d} \tilde{\theta}^{2}}, \quad D_{t}=\frac{E t_{t}^{3}}{12\left(1-v^{2}\right)}$

where $D_{\mathrm{t}}$ is the flexural rigidity. Integrating (32) twice and inserting (33) leads to

$D_{\mathrm{t}} \frac{\mathrm{d}^{2} w_{t}}{\mathrm{~d} \tilde{\theta}^{2}}=\frac{P^{2}}{2} \tilde{\theta}^{2}+c_{1} \tilde{\theta}+c_{2}$

which upon double integration yields

$w_{\mathrm{t}}(\tilde{\theta})=\frac{1}{D_{\mathrm{t}}}\left(\frac{P}{24} \tilde{\theta}^{4}+\frac{c_{1}}{6} \tilde{\theta}^{3}+\frac{c_{2}}{2} \tilde{\theta}^{2}+c_{3} \tilde{\theta}+c_{4}\right)$.

Since the distributed load $P$ is assumed uniform and the deflection of the bump foil is kept zero, the boundary conditions for a section of the top foil between two consecutive bump tops over the length $S$, as depicted in Fig. 8a, are

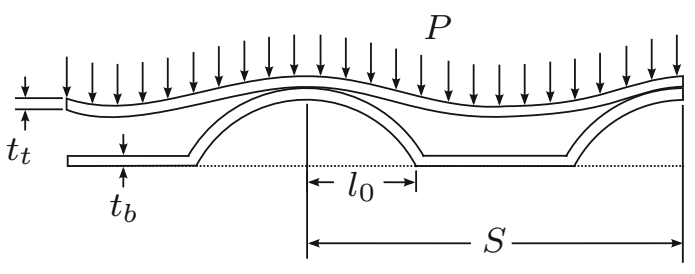

(a) Top foil 'sagging' between bumps

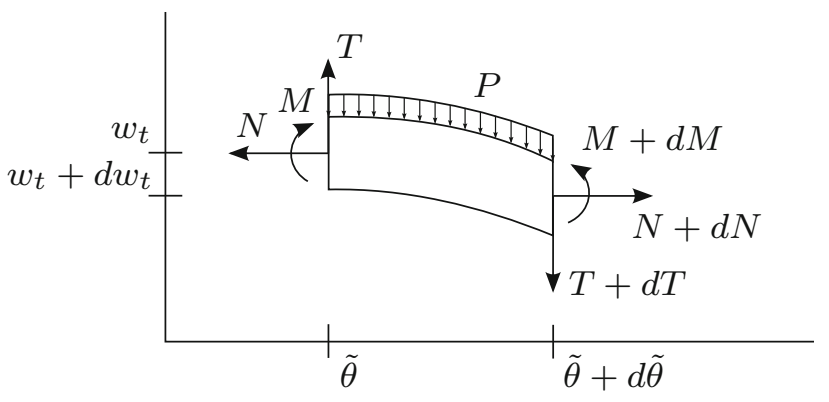

(b) Infinitesimal element of the deformed top foil

Fig. 8 Schematics and nomenclature of a the foil structure (bump foil and top foil) together with an infinitesimal element of the deformed top foil between two consecutive bump tops

$w_{\mathrm{t}}(0)=w_{\mathrm{t}}^{\prime}(0)=w_{\mathrm{t}}(S)=w_{\mathrm{t}}^{\prime}(S)=0$.

Applying these boundary conditions leads to the integration constants $c_{1}=-P S / 2, c_{2}=P S^{3} / 12$ and $c_{3}=c_{4}=0$ which by insertion in (35) leads to the foil deflection function

$w_{\mathrm{t}}(\tilde{\theta})=\left(p-p_{\mathrm{a}}\right) K_{\mathrm{t}}$ 
where $\left(p-p_{\mathrm{a}}\right)=P$ and the top foil flexibility per unit width is

$$
K_{\mathrm{t}}(\tilde{\theta})=\frac{\left(1-v^{2}\right)}{2 E t_{t}^{3}}\left(\tilde{\theta}^{4}-2 S \tilde{\theta}^{3}+S^{2} \tilde{\theta}^{2}\right), \tilde{\theta} \in[0: S] .
$$

The top foil flexibility $K_{\mathrm{t}}(\tilde{\theta})$ is defined over a section of the length $S$, i.e. in a closed interval between two bump tops. To develop an expression for the top foil flexibility over several bump tops, i.e. a periodic expression (38) is expanded into a Fourier series as

$K_{\mathrm{t}}(\tilde{\theta})=\frac{\left(1-v^{2}\right)}{2 E t_{\mathrm{t}}^{3}}\left(\frac{a_{0}}{2}+a_{1} \cos \left(\frac{2 \pi \tilde{\theta}}{S}\right)+\ldots\right)$

where

$$
a_{0}=\frac{S^{4}}{15}, a_{1}=-3\left(\frac{S}{\pi}\right)^{4}, \ldots
$$

It can be shown, that the first two terms of (39) approximate the top foil flexibility with sufficient accuracy and thereby the top foil flexibility per unit width can be written as:

$$
K_{\mathrm{t}}(\tilde{\theta}) \approx \frac{S^{4}\left(1-v^{2}\right)}{E t_{\mathrm{t}}^{3}}\left(\frac{1}{60}-\frac{3}{2 \pi^{4}} \cos \left(\frac{2 \pi \tilde{\theta}}{S}\right)\right)
$$

\section{Appendix 2: Iterative solution based on $\mathrm{NI}$ method}

The pressure $p$ is found iteratively by trying to satisfy the non-linear equilibrium condition [16] which can be written in residual form as:

$R(p)=R_{\text {ext }}(p)-R_{\text {int }}(p)$.
If $p_{i}$ is an approximate solution to the exact solution $p$, then a first-order Taylor expansion gives an equilibrium equation for the next $\mathrm{Nl}$ step as

$$
R\left(p_{i+1}\right) \approx R\left(p_{i}\right)+\frac{\mathrm{d} R_{\text {int }}\left(p_{i}\right)}{\mathrm{d} p} \Delta p_{i}=0 .
$$

If we now define the tangent as

$$
K_{\mathrm{t}} \equiv \frac{\mathrm{d} R_{\text {int }}\left(p_{i}\right)}{\mathrm{d} p}
$$

then the equilibrium equation (43) can be written as

$$
K_{t} \Delta p_{i}=-R\left(p_{i}\right)
$$

or inserting (42)

$$
K_{\mathrm{t}} \Delta p_{i}=-R_{\mathrm{ext}}\left(p_{i}\right)+R_{\mathrm{int}}\left(p_{i}\right) .
$$

When the equilibrium equation (46) has been solved the pressures are updated from

$$
p_{i+1}=p_{i}+\Delta p_{i}
$$

The tangent is then updated with the new pressure $p_{i}=p_{i+1}$ and the procedure is repeated. We repeat until the norm of the residual is sufficiently small. Even though the $\mathrm{Nl}$ method, as shown above, was derived for a scalar problem, it is directly applicable to vector problems as well.

\section{Appendix 3: Solution algorithm}

Based on the iterative $\mathrm{Nl}$ method outlined in Appendix 2, a pseudo algorithm is given as:

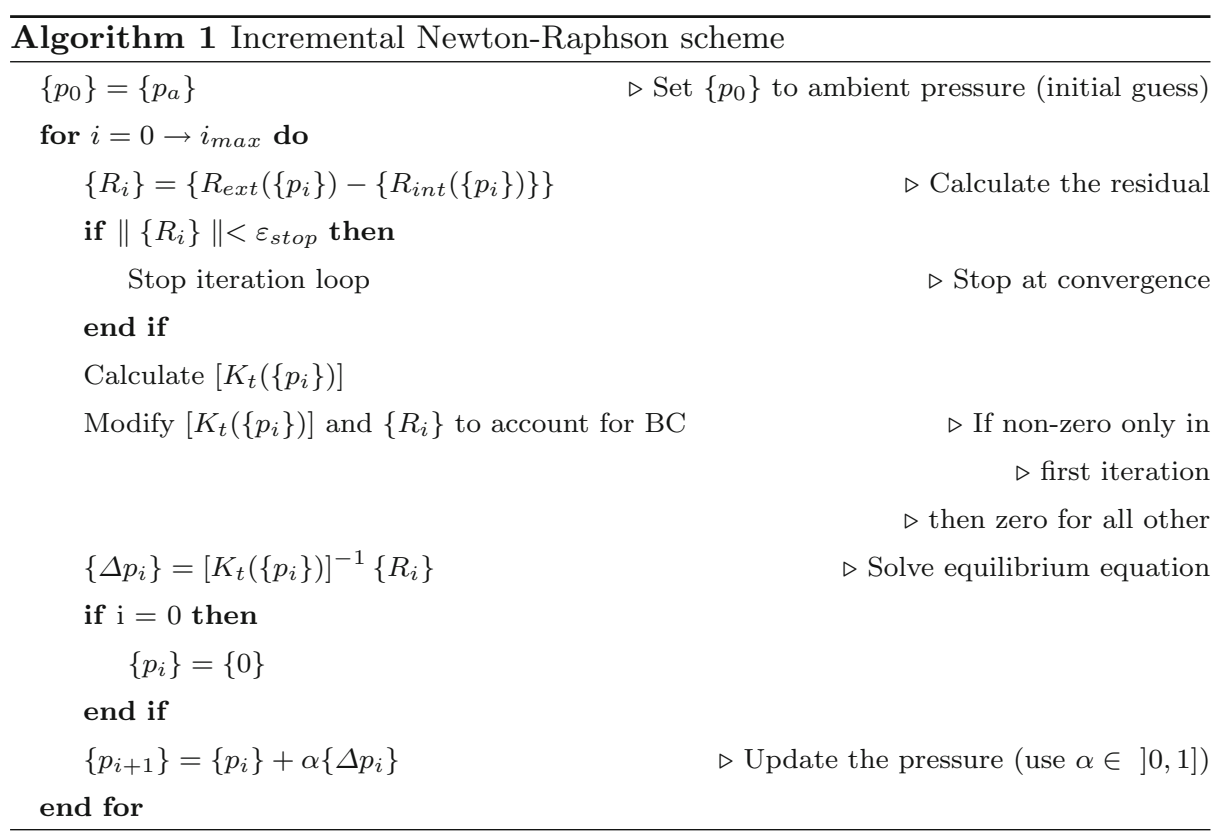




\section{References}

1. Anderson E, Bai Z, Bischof C, Blackford S, Demmel J, Dongarra J, Du Croz J, Greenbaum A, Hammarling S, McKenney A, Sorensen D (1999) LAPACK Users' Guide, 3rd edn. Society for Industrial and Applied Mathematics, Philadelphia

2. Bhore SP, Darpe AK (2013) Nonlinear dynamics of flexible rotor supported on the gas foil journal bearings. J Sound Vib

3. Bruckner RJ (2004) Simulation and modeling of the hydrodynamic, thermal, and structural behavior of foil thrust bearings. $\mathrm{PhD}$ thesis, Case Western Reserve University

4. Carpino M, Talmage G (2006) Prediction of rotor dynamic coefficients in gas lubricated foil journal bearings with corrugated sub-foils. Tribol Trans 49(3):400-409

5. Cook RD, Malkus DS, Plesha ME, Witt JW (2002) Concepts and applications of finite element analysis, 4th edn. Wiley, New York

6. Hamrock BJ (1994) Fundamentals of fluid film lubrication. McGRAW-HILL Series in Mechanical Engineering. McGRAWHILL Inc., New York

7. Hassini MA, Arghir M (2013) A new approach for the stability analysis of rotors supported by gas bearings. In: Proceedings of ASME turbo expo, pp 1-13

8. Heshmat H (1994) Advancements in the performance of aerodynamic foil journal bearings: high speed and load capability. J Tribol 116(2):287-294

9. Heshmat H, Walowit JA, Pinkus O (1983) Analysis of gas lubricated compliant thrust bearings. J Lub Technol 105(4):638-646

10. Heshmat H, Walowit JA, Pinkus O (1983) Analysis of gaslubricated foil journal bearings. J Lub Technol 105(4):647-655

11. Inman DJ (2000) Engineering vibration. Prentice-Hall Inc., New Jersey

12. Kim D (2007) Parametric studies on static and dynamic performance of air foil bearings with different top foil geometries and bump stiffness distributions. J Tribol 129(2):354-364

13. Kim D, Lee AS, Choi BS (2013) Evaluation of foil bearing performance and nonlinear rotordynamics of $120 \mathrm{kw}$ oil-free gas turbine generator. In: Proceedings of ASME turbo expo 2013, pp 1-8

14. Kim D, Park S (2009) Hydrostatic air foil bearings: analytical and experimental investigation. Tribol Int 42(3):413-425

15. Kim TH, San Andrés L (2005) Heavily loaded gas foil bearings: a model anchored to test data. In: ASME conference proceedings, vol 47276, pp 763-771

16. Krenk S (2009) Non-linear modeling and analysis of solids and structures. Cambridge University Press, Cambridge

17. Larsen JS, Santos IF (2013) Compliant foil journal bearings: investigation of dynamic properties. In: Proceedings of 10th international conference on Schwingungen in Rotierenden Maschinen (SIRM2013), pp 1-12, 25-27. ISBN 978-3-00-038602-2, Berlin, Germany
18. Larsen JS, Varela AC, Santos IF (2014) Numerical and experimental investigation of bump foil mechanical behaviour. Tribol Int 74:46-56

19. Le Lez S, Arghir M, Frene J (2007) A new bump-type foil bearing structure analytical model. J Eng Gas Turbines Power 129(4):1047-1057

20. Le Lez S, Arghir M, Frene J (2008) A dynamic model for dissipative structures used in bump-type foil bearings. Tribol Trans 52(1):36-46

21. Lee D, Kim D (2011) Design and performance prediction of hybrid air foil thrust bearings. J Eng Gas Turbines Power 133(4)

22. Lee D, Kim Y-C, Kim K-W (2009) The dynamic performance analysis of foil journal bearings considering coulomb friction: rotating unbalance response. Tribol Trans 52(2):146-156

23. Lund JW (1968) Calculation of stiffness and damping properties of gas bearings. J Lub Technol pp 793-804

24. Peng JP, Carpino M (1993) Calculation of stiffness and damping coefficients for elastically supported gas foil bearings. J Tribol 115(1):20-27

25. Peng JP, Carpino M (1997) Finite element approach to the prediction of foil bearing rotor dynamic coefficients. J Tribol 119(1):85-90

26. Peng ZC, Khonsari MM (2004) Hydrodynamic analysis of compliant foil bearings with compressible air flow. J Tribol 126(3):542-546

27. Ruscitto D, Cormick JM, Gray S (1978) Hydrodynamic air lubricated compliant surface bearing for an automotive gas turbine engine 1: journal bearing performance. Technical Report NASA CR-135368

28. San Andrés L, Kim TH (2007) Improvements to the analysis of gas foil bearings: integration of top foil $1 \mathrm{~d}$ and $2 \mathrm{~d}$ structural models

29. San Andrés L, Kim TH (2009) Analysis of gas foil bearings integrating fe top foil models. Tribol Int 42(1):111-120

30. San Andrés L, Kim TH (2010) Thermohydrodynamic analysis of bump type gas foil bearings: a model anchored to test data. J Eng Gas Turbines Power 132(4):042504

31. Walowit JA, Anno JN (1975) Modern developments in lubrication mechanics. Applied Science, London

32. Walton JF, Heshmat H, Tomaszewski MJ (2007) Design and test program in the developmen of a $100 \mathrm{hp}$ oil-free high-speed blower. In: Proceedings of ASME turbo expo

33. Wang CC (2012) Bifurcation and nonlinear dynamic analysis of united gas-lubricated bearing system. Comput Math Appl 64(5):729-738

34. Xu F, Liu Z, Zhang G, Xie L (2011) Hydrodynamic analysis of compliant foil bearings with modified top foil model

35. Zhang XQ, Wang XL, Zhang YY (2013) Non-linear dynamic analysis of the ultra-short micro gas journal bearing-rotor systems considering viscous friction effects. Nonlinear Dyn pp 1-15

36. Zywica G (2013) The dynamic performance analysis of the foil bearing structure. Acta mechanica et automatica 7(1) 